\title{
EFFECT OF IRRADIATION DAMAGE AND HELIUM ON THE SWELLING AND STRUCTURE OF VANADIUM-BASE ALLOYS*
}

\author{
by
}

H. M. Chung, B. A. Loomis, and D. L. Smith

Argonne National Laboratory

Argonne, IL 60439, U.S.A.

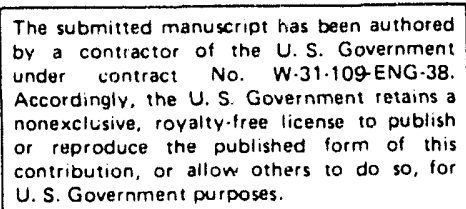

December 1993

\section{DISCLAIMER}

\begin{abstract}
This report was prepared as an account of work sponsored by an agency of the United States Government. Neither the United States Government nor any agency thereof, nor any of their employees, makes any warranty, express or implied, or assumes any legal liability or responsibility for the accuracy, completeness, or usefulness of any information, apparatus, product, or process disclosed, or represents that its use would not infringe privately owned rights. Reference herein to any specific commercial product, process, or service by trade name, trademark, manufacturer, or otherwise does not necessarily constitute or imply its endorsement, recommendation, or favoring by the United States Government or any agency thereof. The views and opinions of authors expressed herein do not necessarily state or reflect those of the United States Government or any agency thereof.
\end{abstract}

To be published in the Proceedings of the Sixth International Conference on Fusion Reactor Materials, September 27-October 1, 1993, Stresa, Italy.

*Work supported by the U.S. Department of Energy, Office of Fusion Energy, under Contract W-31-109-Eng-38. 


\section{Effect of irradiation damage and helium on swelling and structure of vanadium-base alloys*}

H. M. Chung, B. A Loomis, and D. L. Smith

Argonne National Laboratory. Argonne, IL 60439, U.S.A.

e-mail ? ze_chung@qmgate.anl.gov, fax 1708252 3604, tel. 17082525111

Swelling behavior and microstructural evolution of V-Ti, V-Cr-Ti, and V-Ti-Si alloys were investigated after irradiation at $420-600^{\circ} \mathrm{C}$ up to $114 \mathrm{dpa}$. The alloys exhibited swelling maxima between 30 and $80 \mathrm{dpa}$ and swelling decreased on irradiation to higher dpa. This is in contrast to the monotonically increasing swelling of binary alloys that contain $\mathrm{Fe}, \mathrm{Ni}, \mathrm{Cr}, \mathrm{Mo}$, $\mathrm{W}$, and $\mathrm{Si}$. Precipitation of dense $\mathrm{Ti}_{5} \mathrm{Si}_{3}$ promotes good resistance to swelling of the Ti-containing alloys, and it was concluded that Ty of $>3 \mathrm{wt} . \%$ and $400-1000$ wppm Si are necessary to effectively suppress swelling. Swelling was minimal in $\mathrm{V}-4 \mathrm{Cr}-4 \mathrm{~T}$, identified as the most promising alloy based on good mechanical properties and superior resistance to irradiation embrittlement. V-20Ti doped with $B$ exhibited somewhat higher swelling because of He generation. Lithium atoms, generated from transmutation of ${ }^{10} \mathrm{~B}$, formed $\gamma-\mathrm{LiV}_{2} \mathrm{O}_{5}$ precipitates and did not seem to produce undesirable effects on mechanical properties.

"Work supported by the Office of Fusion Energy, U.S. Department of Energy, under Contract W-31-109-Eng-38. 


\section{Introduction}

Vanadium-base alloys have significant advantages over other candidate alloys (such as austenitic and ferritic steels) for use as structural materials in fusion devices, e.g., in the International Thermonuclear Experimental Reactor (ITER) and in magnetic fusion reactors (MFRs) [1-5]. As part of a program to screen candidate alloys and develop an optimal alloy, extensive investigations have been conducted on the swelling behavior, tensile properties, impact toughness, and microstructural evolution of $\mathrm{V}$ alloys after irradiation by fast neutrons [6-14]. From these investigations, V-Cr-T1 alloys containing 5-7 wt.\% Cr, 3-5 at.\% Ti, 400-1000 wt. ppm Si, and <1000 wt. ppm $\mathrm{O}+\mathrm{N}+\mathrm{C}$ were identified as most desirable alloys that exhibit superior resistance to swelling, embrittlement, and hydrogen-induced effects during fast-neutron irradiation in lithium [6-10]. As a result, recent attention has focused primarily on $\mathrm{V}-4 \mathrm{Cr}-4 \mathrm{TI}, \mathrm{V}-$ 5Cr-5Ti, V-5Cr-3Ti, and V-5Ti. Recent studies on tensile properties [11], impact toughness [12], and ductile-brittle transition temperature (DBTT) [12.13] of unirradiated $[13\}$ and irradiated $\{11.12\}$ specimens showed excellent mechanical properties and superior resistance to irradiation-induced embrittlement of some of these alloys, in particular $\mathrm{V}-4 \mathrm{Cr}-4 \mathrm{Ti}$ and $\mathrm{V}-5 \mathrm{Ti}$. Thermal creep behavior of $\mathrm{V}-4 \mathrm{Cr}-4 \mathrm{Ti}$ has been also reported to be superior to those of austenitic and ferritic steels [14]. For these alloys. however, no data base has been renorted on irradiation-induced swelling. In the work reported here. irradiation-induced density change and microstructural evolution of a number of the promising binary and ternary alloys were investigated after irradiation at $420-600^{\circ} \mathrm{C}$ up to $114 \mathrm{dpa}$ in the Fast Flux Test Facility (FFTF).

One of the properties of the V-based alloys that is not yet well understood is the effect of simultaneous generation of He and neutron damage under conditions relevant to fusion-reactor operation [15-29]. Several methods have been utilized in the past to 
simulate the effect of He generation in neutron-irradiated $V$ alloys, i.e., the "tritiumtrick" technique [15-19]. cyclotron-injection of helium [20-23,26], B-doping technique [24-27], and dynamic helium charging experiment [28-29]. The B-doping technique utilizes the large thermal-neutron cross section ( $\approx 3840$ barn) of the ${ }^{10} \mathrm{~B}(\mathrm{n}, \alpha)^{7} \mathrm{LI}$ reaction. By adjusting the level of doped ${ }^{10} \mathrm{~B}$, the method can be tailored conveniently to suit the characteristic neutron spectrum of a fission reactor. However, to assess the viability of the technique and to understand the effect of the Li by-product on the swelling and mechanical properties, it is necessary to understand the behavior of not only He microvoids but also of $\mathrm{B}$ and $\mathrm{Ll}$ atoms during irradiation. For this purpose, a comparative study of the microstructural evolution and density change was also included in this work on specimens that were irradiated with and without B-doping.

\section{Materials and procedures}

Density measurements and transmission electron microscopy (TEM) were conducted on standard-size disk specimens irradiated in the FFTF. The chemical composition of the alloys is given in Table 1 . The content of $\mathrm{B}$ in the disk specimens of V-2OTi (BL-15), dissolved in the alloy as an inadvertent impurity, was not known prior to irradiation. The disks were irradiated at 425,520 , and $600^{\circ} \mathrm{C}$ to neutron

fluences $(E>0.1 \mathrm{MeV})$ of $7.8 \times 10^{22} \mathrm{n} \mathrm{cm}^{-2}(\approx 44 \mathrm{dpa})$ and $\left.1.9 \times 10^{23} \mathrm{ncm}^{-2} \Leftrightarrow 114 \mathrm{dpa}\right)$. They were sealed in TZM capsules filled with $99.99 \%$-enriched ${ }^{7} \mathrm{Li}$ during irradiation to prevent contamination with $\mathrm{O}, \mathrm{N}$, and $\mathrm{C}$ impurities dissolved in the Na coolant of the FFTF and formation of unacceptable levels of $\mathrm{He}$ and $\mathrm{T}$ from ${ }^{6} \mathrm{Li}$.

\section{Results and discussion}

\subsection{Density Change}


Table 1. Composition of vanadium alloys irradiated in fast flux test facility materials open test assembly

\begin{tabular}{|c|c|c|c|c|c|}
\hline \multirow[b]{2}{*}{ ANL ID } & \multirow{2}{*}{$\begin{array}{c}\text { Nominal } \\
\text { Composition } \\
(w t . \%)\end{array}$} & \multicolumn{4}{|c|}{ Concentration (wt. ppm) } \\
\hline & & $\mathrm{O}$ & $\mathrm{N}$ & $\mathrm{C}$ & $\mathrm{Si}$ \\
\hline$\overline{B L-11}$ & $4.9 \mathrm{Ti}$ & 1820 & 530 & 470 & 220 \\
\hline$B L-46$ & $4.6 \mathrm{Ti}$ & 305 & 53 & 85 & 160 \\
\hline BL-34 & $8.6 \mathrm{Ti}$ & 990 & 180 & 420 & 290 \\
\hline BL-12 & $9.8 \mathrm{Ti}$ & 1670 & 390 & 450 & 245 \\
\hline BL- 13 & $14.4 \mathrm{Ti}$ & 1580 & 370 & 440 & 205 \\
\hline $\mathrm{BL}-15^{\mathrm{a}}$ & $17.7 \mathrm{Ti}$ & 830 & 160 & 380 & 480 \\
\hline$B L-16$ & $20.4 \mathrm{Ti}$ & 390 & 530 & 210 & 480 \\
\hline BL-2I & $13.7 \mathrm{Cr}-4.8 \mathrm{Ti}$ & 340 & 510 & 180 & 1150 \\
\hline BL.22 & $13.4 \mathrm{Cr}-5.1 \mathrm{Ti}$ & 300 & 52 & 150 & 56 \\
\hline BL-23 & $12.9 \mathrm{Cr}-5.9 \mathrm{Ti}$ & 400 & 490 & 280 & 1230 \\
\hline BL-24 & $13.5 \mathrm{Cr}-5.2 \mathrm{Ti}$ & 1190 & 360 & 500 & 390 \\
\hline $\mathrm{BL}-40$ & $10.9 \mathrm{Cr}-5.0 \mathrm{Ti}$ & 470 & 80 & 90 & 270 \\
\hline$B L-43$ & $9.2 \mathrm{Cr}-4.9 \mathrm{Ti}$ & 230 & 31 & 100 & 340 \\
\hline $\mathrm{BL}-4$ & $9.9 \mathrm{Cr}-9.2 \mathrm{Ti}$ & 300 & 87 & 150 & 270 \\
\hline $\mathrm{BL}-47$ & $4.1 \mathrm{Cr}-4.3 \mathrm{Ti}$ & 350 & 220 & 200 & 870 \\
\hline $\mathrm{BL} \cdot 27$ & $3.1 \mathrm{Ti}-0.25 \mathrm{Si}$ & 210 & 310 & 310 & 2500 \\
\hline $\mathrm{BL}-42$ & $3.1 \mathrm{Ti}-0.5 \mathrm{Si}$ & 580 & 190 & 140 & 5400 \\
\hline$B L-15$ & $2.5 \mathrm{Ti}-1 \mathrm{Si}$ & 345 & 125 & 90 & 9900 \\
\hline
\end{tabular}

aContains a significant level of boron as impurity.

Swelling of V-Ti, V-Cr-Ti, and V-Ti-Si alloys, determined from density measurements after irradiation at 420 and $600^{\circ} \mathrm{C}$, is shown as a function of irradiation damage (dpa) in Figs. 1-3, respectively. Most of the Ti-containing alloys exhibited swelling maxima in the damage range of 30-80 dpa. When irradiated to higher dpa. swelling in these alloys decreased monotonically. For irradiation at $600^{\circ} \mathrm{C}$, sufficient data for higher dpa were not available for some of the alloys, and it was not possible to verify whether swelling actually decreased or saturated at higher dpa. The anomalous behavior that exhibited actual decrease of swelling (i.e.. increase of density) is in 
distinct contrast to the normal swelling of other binary alloys of $\mathrm{V}$ containing $\mathrm{Fe}, \mathrm{Ni}$, Cr, Mo, W. and Si, which increases monotonically for increasing dpa [7,10]. Closer examination of Figs. 1 and 2 indicates the tendency for a higher content of Ti (except the B-containing V-2OTi $[\mathrm{BL}-15])$ to lower maximum swelling in the V-Ti binary alloys, whereas a higher content of $\mathrm{Cr}$ is conducive to a higher level of swelling maxima in the $\mathrm{V}$-Cr-Ti ternary alloys. Therefore. $\mathrm{Cr}$ addition $>9 \mathrm{wt} . \%$ in the ternary alloys is not desirable from the standpoint of not only irradiation embrittlement but also of irradiation-induced swelling.
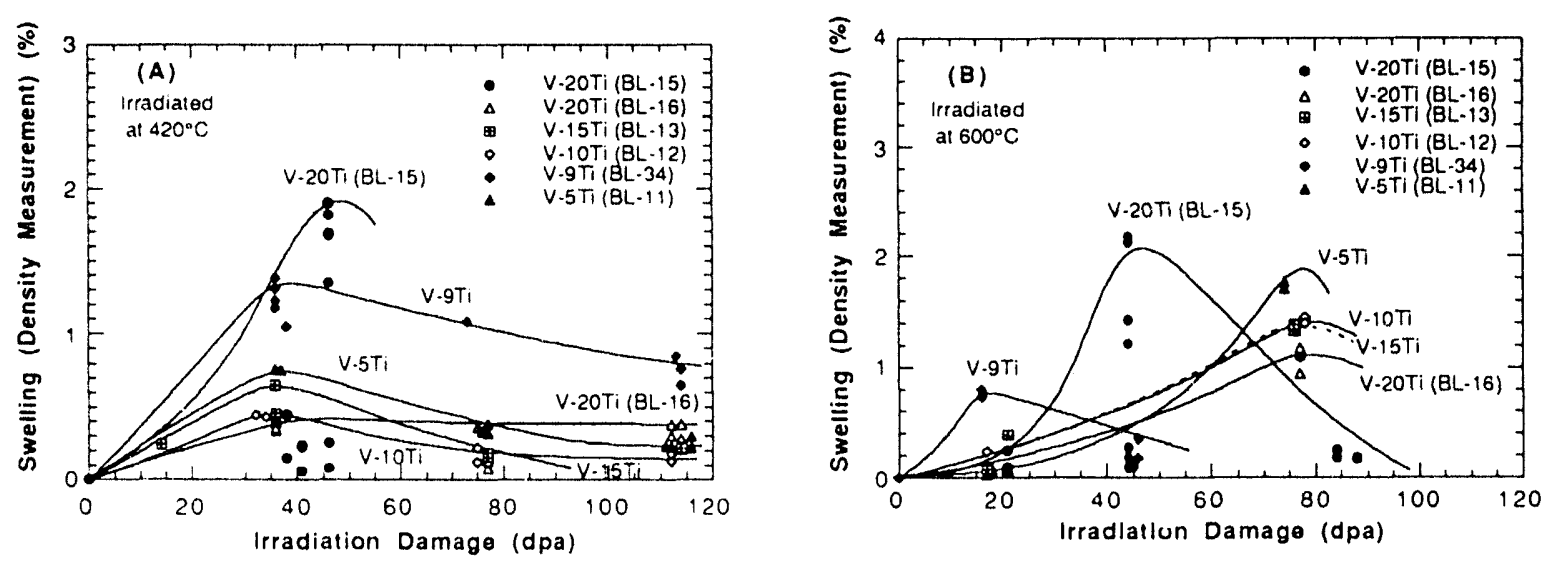

Fig. 1. Density change of V-Ti alloys as function of dose (dpa) after irradiation at $420(\mathrm{~A})$ and $600^{\circ} \mathrm{C}(\mathrm{B})$
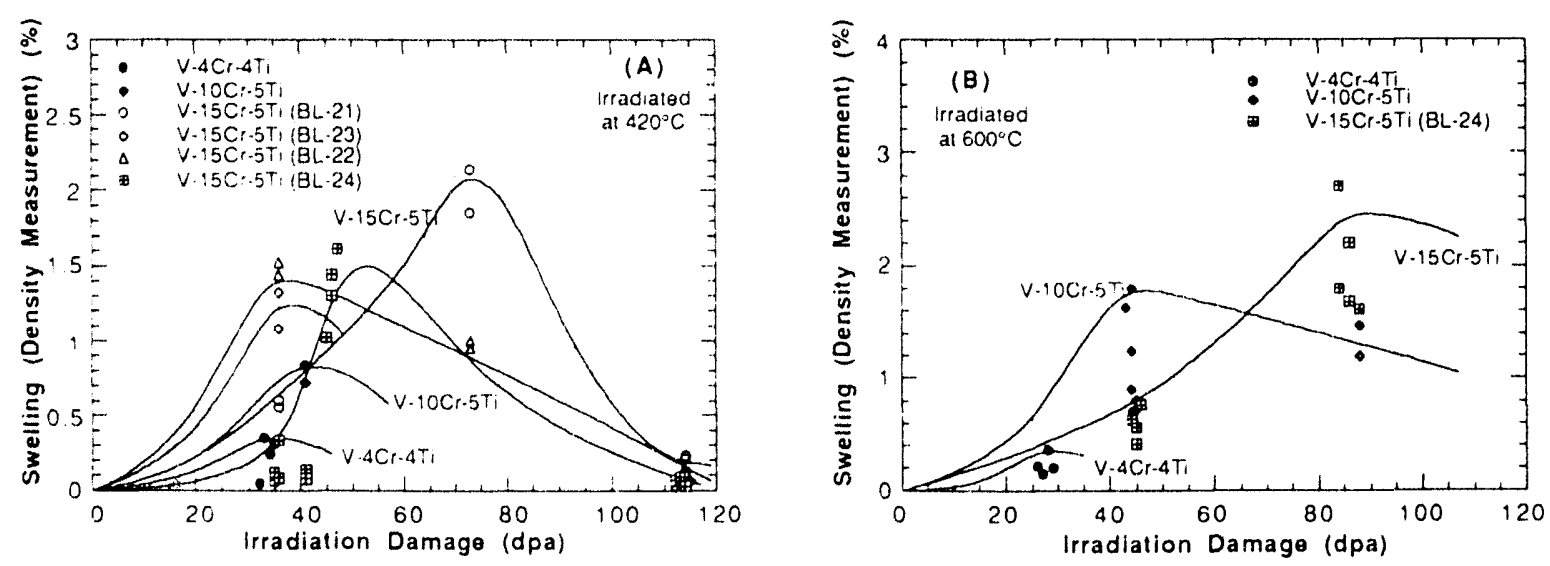

Fig. 2. Density change of $\mathrm{V}-\mathrm{Cr}-\mathrm{Ti}$ alloys as function of dose (dpa) after irradiation at $420(\mathrm{~A})$ and $600^{\circ} \mathrm{C}(\mathrm{B})$ 

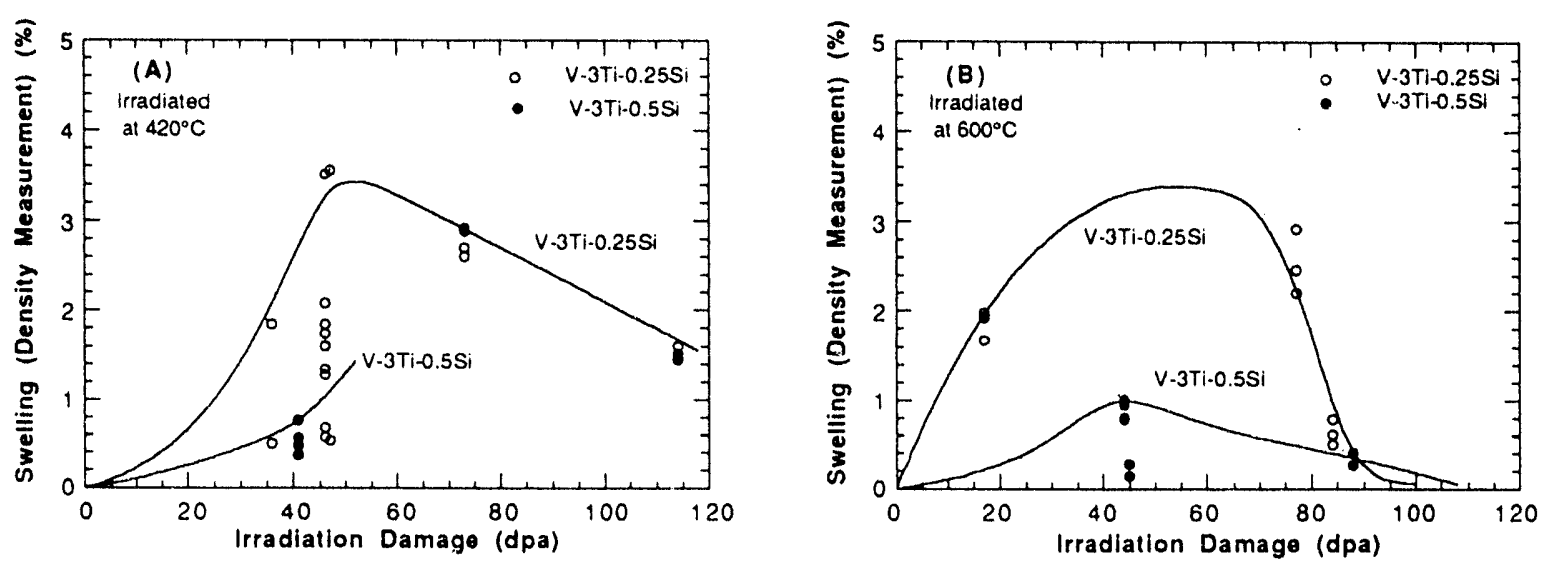

Fig. 3. Density change of V-3Ti-Si alloys as function of dose (dpa) after irradiation at $420(\mathrm{~A})$ and $600^{\circ} \mathrm{C}(\mathrm{B})$

Swelling of the V-3Ti-0.25Si and V-3Ti-0.5Si alloys was relatively higher despite the high level of $\mathrm{Si}$. These alloys are known to exhibit relatively higher yield [13] and creep [30] strengths, which have been attributed to a tendency to form a relatively high density of Ti(O,N.C) precipitates [13]. Therefore, unless the combined impurity level of $O, N, C, S$. and $P$ is extremely low, virtually all of the Ti solutes in the alloys could be tied up in Ti-based precipitates. This will prevent dense precipitation of ultrafine $\mathrm{Ti}_{5} \mathrm{Si}_{3}$ particles, to which the resistance to swelling of Ti-containing alloys has been attributed [9]. In V-3Ti-0.25Si, $\mathrm{Ti}_{5} \mathrm{Si}_{3}$ precipitates were not observed [31]. Ti(O,N,C) precipitates were reported to be absent in Ti-containing vanadium alloys when $\mathrm{O}+\mathrm{N}+\mathrm{C}$ content is $<400 \mathrm{wppm}[32$ ]. Therefore, it is expected that, by limiting the impurity content of the V-3Ti-Si alloys to below $<400 \mathrm{wppm}$, swelling can be suppressed in the alloys. However, Loomis et al have reported that high Si content in the V-3Ti-Si alloys is conducive to higher DBTT and increased effects of $\mathrm{H}[12]$.

Swelling resistance of the $\mathrm{V}-4 \mathrm{Cr}-4 \mathrm{Ti}$ alloy was excellent $(<0.4 \%$ for $<120 \mathrm{dpa})$. This is shown in Fig. 4. V-4Cr-4Ti, designated as one the primary candidate alloys, also exhibited an excellent resistance to irradiation embrittlement; after irradiation to $\approx 34$ 
dpa at 420,520 , and $600^{\circ} \mathrm{C}, \mathrm{DBTT}$ remained below $-196^{\circ} \mathrm{C}[12]$. Uniform and total elongations of the alloy, when measured at room temperature after the same irradiations, were 8.1 and $10.2 \%$, respectively [11]. Thermal creep behavior of the alloy was also excellent compared with those of austenitic and ferritic/martensitic steels [14].

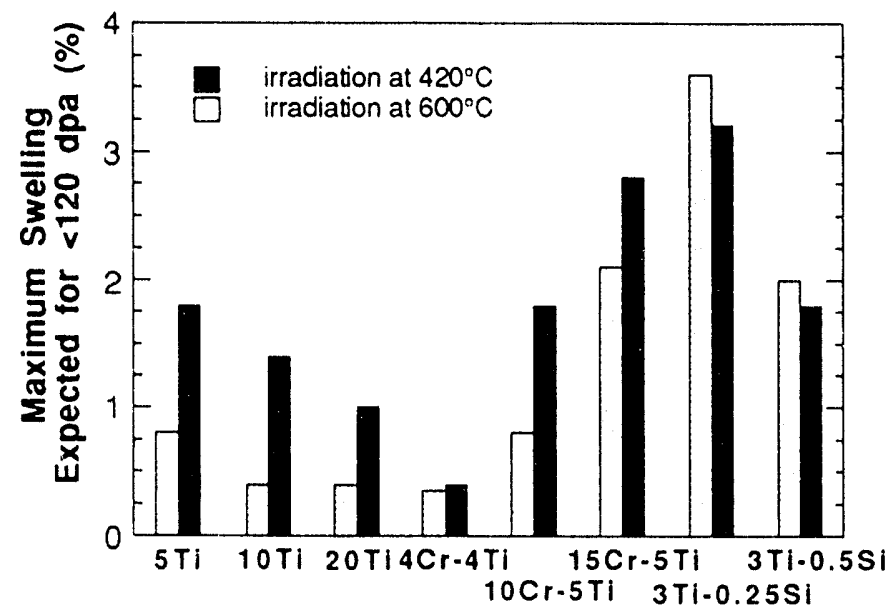

Fig. 4. Maximum swelling (density change) of several vanadium-base alloys for irradiation at $420-600^{\circ} \mathrm{C}$ up to $\approx 120$ dpa

\subsection{Model of swelling kinetics}

The Ti-containing alloys that exhibited relatively low swelling contained highdensity ultrafine precipitates of $\mathrm{Ti}_{5} \mathrm{Si}_{3}$. Some of the examples of the dark-field images of $\mathrm{Ti}_{5} \mathrm{Si}_{3}$ precipitates are shown in Fig. 5. Swelling in the specimens containing dense $\mathrm{Ti}_{5} \mathrm{Si}_{3}$ was relatively low except for the B-containing V-2OTi $(\mathrm{BL}-15)$ irradiated at $420^{\circ} \mathrm{C}$ to $46 \mathrm{dpa}$. In V-3Ti-0.25Si, which produced dense microvoids upon irradiation at $420^{\circ} \mathrm{C}$ to 114 dpa (density change $\approx 1.6 \%$ ), precipitation of $\mathrm{Ti}_{5} \mathrm{Si}_{3}$ was negligible.

Void swelling and density change in Ti-containing alloys were generally consistent and could be correlated well with the number density of the ultrafine $\mathrm{Ti}_{5} \mathrm{Si}_{3}$ 

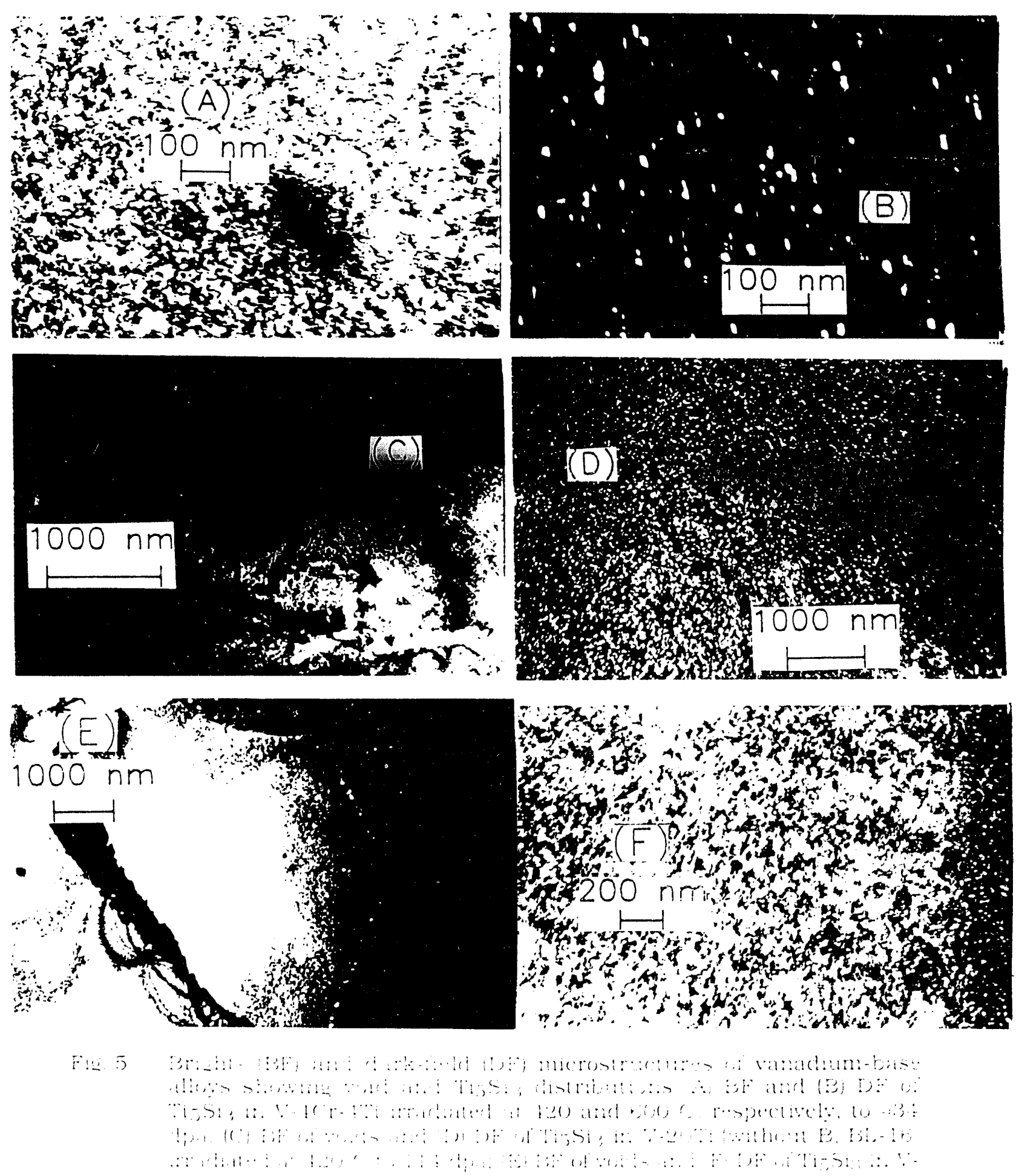
precipitates. That is, a greater number density of the precipitates is conducive to lower swelling during irradiation. This could be attributed to the large interface area generated between the matrix and high-density precipitates of $\mathrm{Ti}_{5} \mathrm{Si}_{3}$. This interface area is believed to act as an efficient sink for vacancies and thereby inhibits nucleation and growth of voids.

Anomalous swelling behavior has also been reported by Maziasz [33] for some heats of $14 \mathrm{Cr}-16 \mathrm{Ni}-2.5 \mathrm{Mo}-2 \mathrm{Mn}$ austenitic stainless steels stabilized by addition of $\approx 0.25 \% \mathrm{Ti}$ with and without $\mathrm{P}$ doping. In these steels, swelling reached maxima of $\approx 2 \%$ at $=34 \mathrm{dpa}$ and decreased to $0.6-1.1 \%$ at $57 \mathrm{dpa}$. The decrease of swelling was accompanied by high-density precipitation of ultrafine MC carbides. According to Maziasz [33]. such profound microstructural changes could disrupt the balance between sink strengths of dislocations, voids, and precipitates, so that MC precipitates and voids now become the dominant sinks for vacancies and interstitials. The breakdown of the steady-state biased partitioning of defects then would lead to increased defect recombination at the large interface area between matrix and precipitates, which would lead to reduction or elimination of the vacancy supersaturation. Dramatic changes in microstructure, defect partitioning, and recombination behavior could cause the critical radius of voids (necessary to maintain stability) to increase enough so that small existing voids would become unstable. When this occurs, existing subcritical-size voids will stop growing or actually begin shrinking with increasing damage level, and further nucleation of voids will be prevented.

The anomalous swelling maxima of the V-base alloys could be explained in a similar manner, with the high-density ultrafine precipitates of $\mathrm{Ti}_{5} \mathrm{Si}_{3}$ playing a role similar to that of $\mathrm{MC}$ carbide in the steels. Apparently, the dramatic changes in microstructure, sink density, and upset of the steady-state biased partitioning of defects are produced only when the size of the ultrafine precipitates is comparable to 
those of critical-size microvoids and precipitation occurs in very high density, e.g., those in Fig. 5. According to this model, the depende nce of swelling on damage level is expected to be strongly influenced by the kinetics of the irradiation-induced precipitation of $\mathrm{Ti}_{5} \mathrm{Si}_{3}$ phase, as illustrated in Fig. 6.
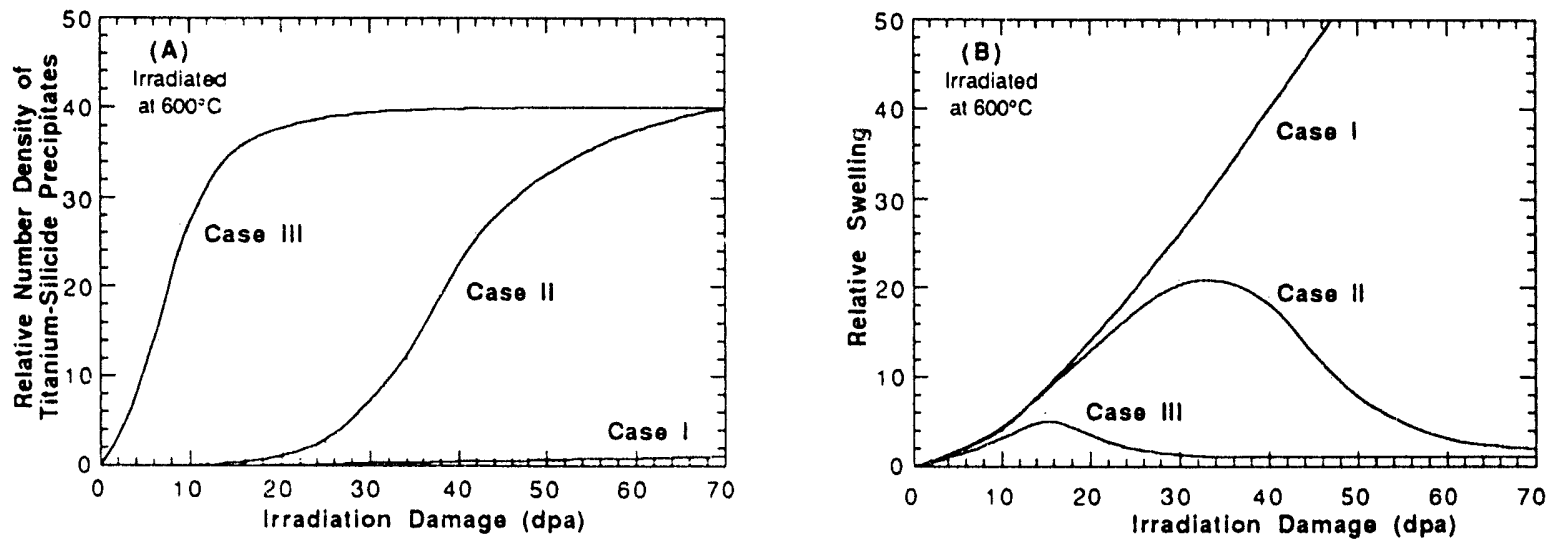

Fig. 6. Schematic illustration of relationship between kinetics of $\mathrm{Ti}_{5} \mathrm{Si}_{3}$ precipitation (A) and swelling (B) as function of irradiation damage in Ticontaining vanadium alloys

\subsection{Effect of boron-doping and helium production}

Void swelling and density change in the B-containing V-2OTi alloy (BL-15) were found to be significantly higher than that of the similar V-2OTi alloy (BL-16) that did not contain B. This is shown in more detail in Figs. 5 (voids) and 7 (density change). Evidently, the higher swelling is a result of He generation in the B-containing alloy from transmutation of ${ }^{10} \mathrm{~B}$. However, sink strength of the ultrafine $\mathrm{Ti}_{5} \mathrm{Si}_{3}$ precipitates in both alloys was so strong after irradiation to $114 \mathrm{dpa}$ that swelling was decreased to $<0.4 \%$ at the high dose.

The irradiated specimens of the B-containing V-20Ti alloy exhibited a hitherto unknown peculiar microstructural feature. As an example, characteristic TEM 

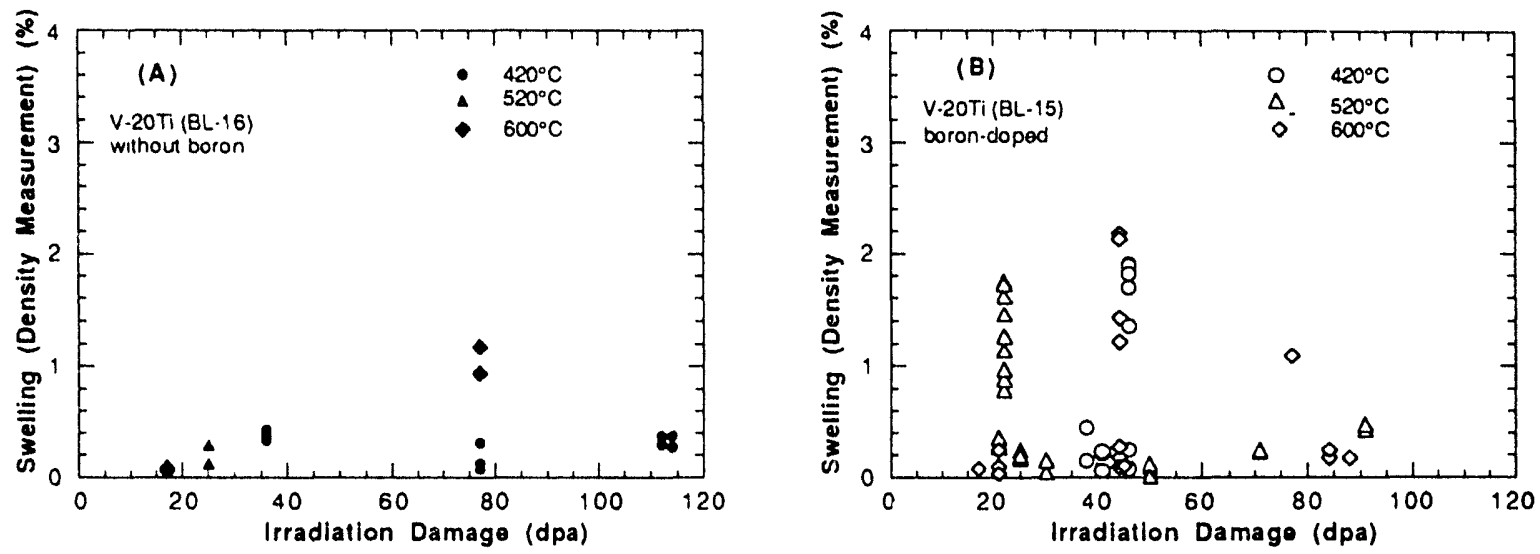

Fig. 7. Density change of V-20Ti (A) without B (BL-16) and (B) with B impurity (BL15) as function of dose (dpa) after irradiation at 420,520 , and $600^{\circ} \mathrm{C}$

microstructures observed in the specimens irradiated to $\approx 44$ and $\approx 80$ dpa are shown in Fig. 8. The morphology of the shells visible in Fig. 8A is strikingly similar to that of the cylindrical damage shells reported by Rau and Ladd [35] for neutron-irradiated V doped with $<10$ wppm B. The shell-shaped and nearby globular features observed in Fig. 8 indicate a secondary precipitation that occurred in association with the damage zones reported by Rau and Ladd [35]. To positively identify the nature of the precipitates. SAD and dark-field-imaging analyses were conducted. The result showed [36] that the precipitates are the $\gamma-\mathrm{LiV}_{2} \mathrm{O}_{5}$ phase [37]. Based on the result of the present study and information reported by Rau and Ladd [35], the behavior of B and Li can be summarized by the schematic illustration in Fig. 9.

According to the phase diagram reported in the literature [38], there is no solubility between $\mathrm{V}$ and $\mathrm{Li}$ in the solid or liquid state. Therefore, virtually all $\mathrm{Li}$ atoms produced from the transmutation are expected to present themselves in $\mathrm{Li}_{\mathrm{x}} \mathrm{V}_{2} \mathrm{O}_{5}$ precipitates. Consequently, grain-boundary segregation of Li is not likely to occur. Solubility of B in V-base alloys is also very low 127,351 . Boron atoms seem to be distributed more or less uniformly either in solid solution or in small $\mathrm{V}_{3} \mathrm{~B}_{2}$ 

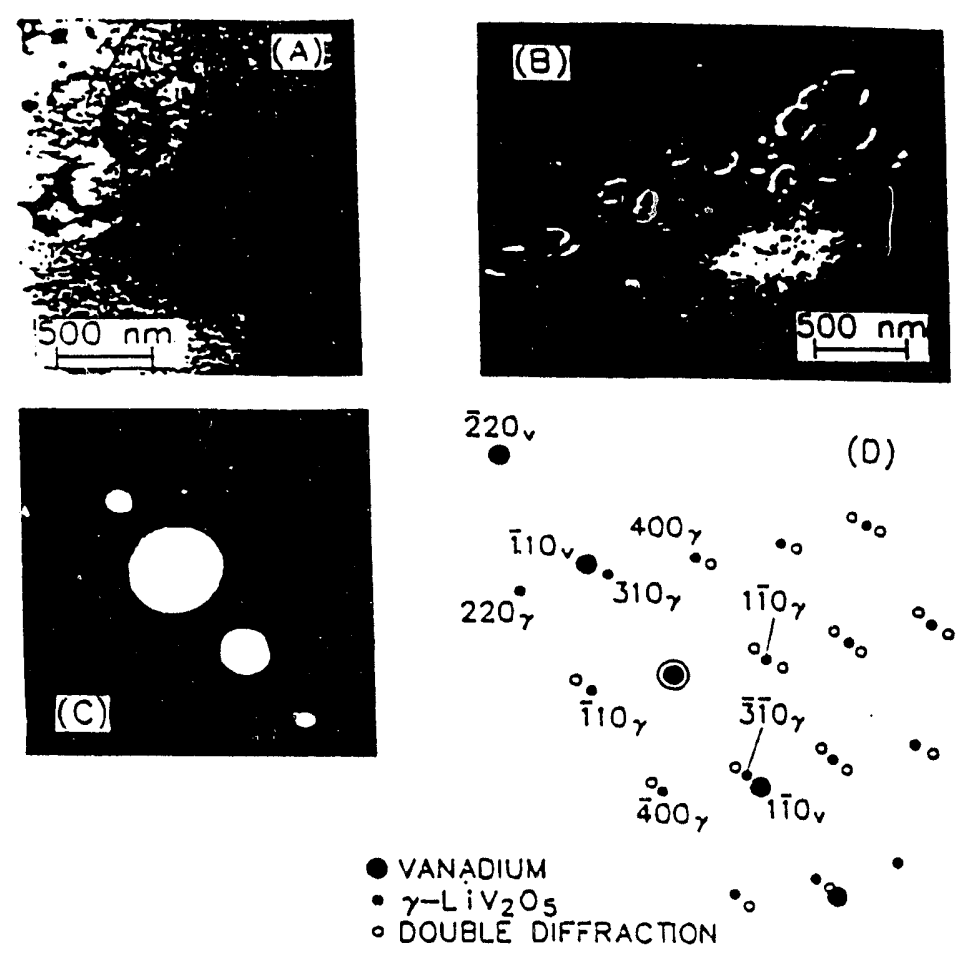

Fig. 8. Shell-shaped $\gamma-\mathrm{LIV}_{2} \mathrm{O}_{5}$ precipitates observed in $\mathrm{B}$ containing V-20Ti (BL-15) after irradiation at $600^{\circ} \mathrm{C}(\mathrm{A})$ to $=44 \mathrm{dpa}$ (bright-field) and (B) to $\approx 80 \mathrm{dpa}$ (dark-field); (C) SAD pattern of (B): and (D) indexed pattern of (C), showing reflections from $\gamma-\mathrm{LiV}_{2} \mathrm{O}_{5}$ and double-diffraction spots.

(A)

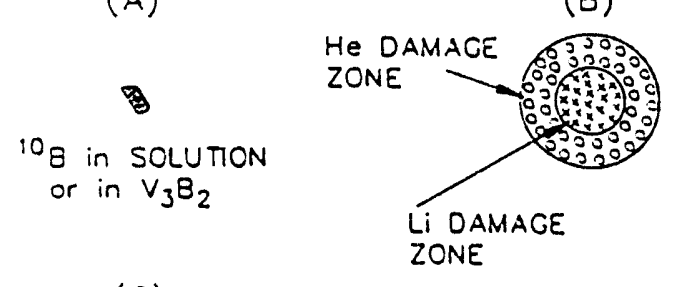

(C)

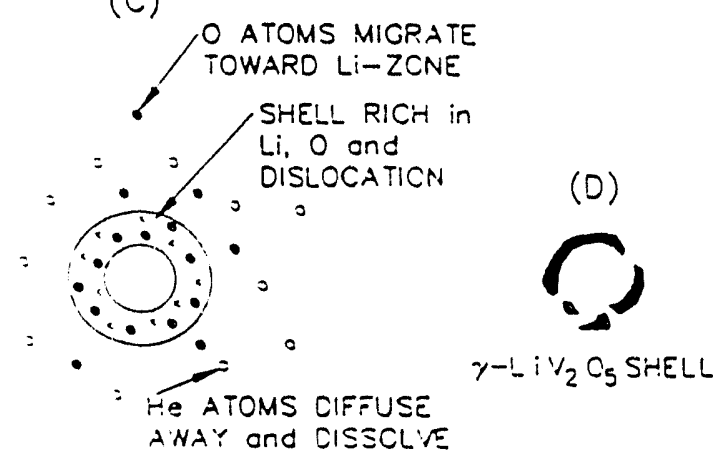

Fig. 9 Schematic illustration of microstructural evolution associated with transmutation of $B$. 
precipitates, and no evidence of grain-boundary segregation of B has been reported. This brhavior of Li and $B$, therefore, seems to strongly support the viability of the ${ }^{10} \mathrm{~B}$ doping technique. Similar to the distribution of B and Li. He-induced microvoids in the B-doped specimens were also distributed more or less uniformly within the grains (Fig. 5E). This is in distinct contrast to the grain-boundary distribution of microvoids that were produced in the He-charged specimens by the tritium-trick technique [15-17].

\section{Conclusions}

1. Resistance to irradiation-induced swelling of $\mathrm{V}-4 \mathrm{Cr}-4 \mathrm{Ti}$, identified as the most promising candidate alloy primarily on the basis of good mechanical properties and superior resistance to irradiation embrittlement and creep, was excellent. Swelling of the alloy is expected to be minimal for the design life of ITER.

2. Ti-containing alloys exhibited anomalous swelling maxima in the damage range of 30-80 dpa. When irradiated to higher dpa, swelling in these alloys decreased monotonically.

3. Dense precipitation of ultrafine $\mathrm{Ti}_{5} \mathrm{Si}_{3}$ is conducive to low swelling. The anomalous swelling behavior seems to be caused by the profound microstructural evolution associated with the dense precipitation of ultrafine $\mathrm{Ti}_{5} \mathrm{Si}_{3}$.

4. Swelling of B-doped V-2OTi was somewhat higher than that of similar alloy not doped with B. However, grain-boundary segregation of B, Li, or He-induced voids was absent, although $\gamma-\mathrm{LiV}_{2} \mathrm{O}_{5}$ precipitates were observed in grains. These microstructural characteristics are consistent with the observation of the insignificant effect of He on mechanical properties of the alloy.

\section{Acknowledgments}

The authors are gratelul to L. J. Nowicki and J. Gazda for their contributions to 
experimental efforts. This work was supported by the Office of Fusion Energy, U. S. Department of Energy, under Contract W-31-109-Eng-38. The authors thank Dr. F. W. Wiffen for helpful discussions.

\section{References}

[1] T. Noda. F. Abe, H. Araki, and M. Okada. J. Nucl. Mater. 155-157 (1988) 581.

[2] R. Santos. J. Nucl. Mater. 155-157 (1988) 589.

(3) S. J. Piet et al.. J. Nucl. Mater. 141-143 (1986) 24.

[4] F. L. Yaggee. E. R. Gilbert, and J. W. Styles, J. Less-Comm. Met. 19 (1969) 39.

[5] D. L. Smith. B. A. Loomis, and D. R. Diercks, J. Nucl. Mater. 135 (1985) 125.

[6] B. A. Loomis, A. B. Hull, and D. L. Smith. J. Nucl. Mater. 179-181 (1991) 148-154.

[7] B. A. Loomis and D. L. Smith. J. Nucl. Mater. 191-194 (1992) 84-91.

[8] H. M. Chung and D. L. Smith, J. Nucl. Mater. 191-194 (1992) 942-947.

(9] H. M. Chung. B. A. Loomis, and D. L. Smith, in: Effects of Radiation on Materials: 16th International Symposium. ASTM STP 1175. A. S. Kumar, D. S. Gelles, R. K. Nanstad, and T. A. Little, eds. (American Society for Testing and Materials, Philadelphia, 1993)

[10] D. L. Smith. B. A. Loomis, and H. M. Chung, in: Plasma Devices and Operations, Vol 3, 1992.

[11] B. A. Loomis. L. J. Nowicki, and D. L. Smith. "Effects of Neutron Irradiation on Tensile Properties of V-Cr-Ti Alloys," this conference; also in: Fusion Reactor Materials Semiannual Progress Report for Period Ending September 30. 1993, DOE/ER-0313/15, Oak Ridge National Laboratory, Oak Ridge, TN, in press.

(12) B. A. Loomis. H. M. Chung. L. J. Nowicki, and D. L. Smith, "Effects of Neutron Irradiation and Hydrogen on Ductile-Brittle Transition Temperatures of VCr-Ti Alloys," ibid.

[13] B. A. Loomis, J. Gazda, and D. L. Smith, "Relationship of Microstructure and Mechanical Properties for V-Cr-Ti Alloys," ibid.

[14] H. M. Chung. B. A. Loomis, and D. L. Smith, "Creep Properties of Vanadium-Base Alloys." ibid.

[15] D. N. Braski, in: Influence of Radiation on Material Properties. ASTM-STP 956 (1986) pp. $271-290$.

[16] D. N. Braski, J. Nucl. Mater. 141-143(1986) 1125.

[17] D. N. Braski, in: Reduced Activation Materials for Fusion Reactors, ASTM-STP 1047 (1988) pp. 161-178. 
[18] H. Matsui, M. Tanaká, M. Yamamoto, and M. Tada, J. Nucl. Mater. 191-194 (1992) 919.

[19] M. Satou, K. Abe, and H. Matsui, J. Nucl. Mater. 191-194 (1992) 938.

[20] W. van Witzenburg, A. Mastenbroek, and J. D. Ellen, J. Nucl. Mater. 103-104 (1981) 1187.

[21] M. P. Tanaka, E. E. Bloom, and J. A. Horak, J. Nucl. Mater. 114 (1981) 895.

[22] M. L. Grossbeck and J. A. Horak, in: Influence of Radiation on Material Properties, ASTM-STP 956 (1986) 291.

[23] J. M. Vitek, D. N. Braski, and J. A. Horak, J. Nucl. Mater. 141-143 (1986) 982.

[24] L. L. Horton and K. Farrell, J. Nucl. Mater. 122-123 (1984) 687.

[25] H. Kawanishi and S. Ishino, in: Reduced Activation Materials for Fusion Reactors. ASTM-STP 1047 (1988) pp. 179-189.

[26] W. van Witzenburg and E. de Vries, in: Effects of Radiation on Materials $\mathrm{A}_{2}$ ASTMSTP 1125 (1990).

[27] H. Kawanishi, Y. Arai, and S. Ishino, J. Nucl. Mater. 191-194 (1992) 933.

[28] D. L. Smith, H. Matsui. L. R. Greenwood, and B. A. Loomis. J. Nucl. Mater. 155157 (1988) 1359.

[29] D. L. Smith, B. A. Loomis, H. Matsui, M. L. Hamilton, K. L. Pearce, J. P. Kopasz, C. E. Johnson, R. G. Clemmer, and L. R. Greenwood, in: Fusion Reactor Materials, Semiannual. Prog. Report. DOE/ER-0313/10, Oak Ridge National Laboratory, Oak Ridge, TN (1991) 159.

[30] D. Harrod and R. Gold. Int. Met. Rev. 25 (1980) 163-221.

[31] H. M. Chung. L. J. Nowicki, and D. L. Smith, in: Fusion Reactor Materials, Semiannual. Prog. Report. DOE/ER-0313/11, Oak Ridge National Laboratory, Oak Ridge, TN (1992) 215-226.

[32] M. Satou and H. M. Chung, in: Fusion Reactor Materials, Semiannual. Prog. Report. DOE/ER-0313/13, Oak Ridge National Laboratory, Oak Ridge, TN (1993) 227-234.

[33] P. J. Maziasz, in: Fusion Reactor Materials. Semiannual. Prog. Report. DOE/ER0313/12, Oak Ridge National Laboratory, Oak Ridge. TN (1992), 163-174.

[34] G. Frommeyer, R. Rosenkran\%, and C. Luedecke, Z. Metallkunde 81 (1990) 307.

[35] R. C. Rau and R. L. Ladd. J. Applied. Phys. 40 (1969) 2899.

[36] H. M. Chung, in: Fusion Reactor Materials, Semiannual. Prog. Report. DOE/ER0313/14. Oak Ridge National Laboratory, Oak Ridge, TN (1993), pp. 299-305.

[37] P. Hagenmuller, J. Galy, M. Pouchard, and A. Casalot, Mat. Res. Bulletin 1 (1966) 45.

[38] T. B. Massalski, J. L. Murray, L. H. Benett, and H. Baker (Eds.), Binary Alloy Phase Diagrams. (American Society for Metals, Metals Park, OH, 1986) 

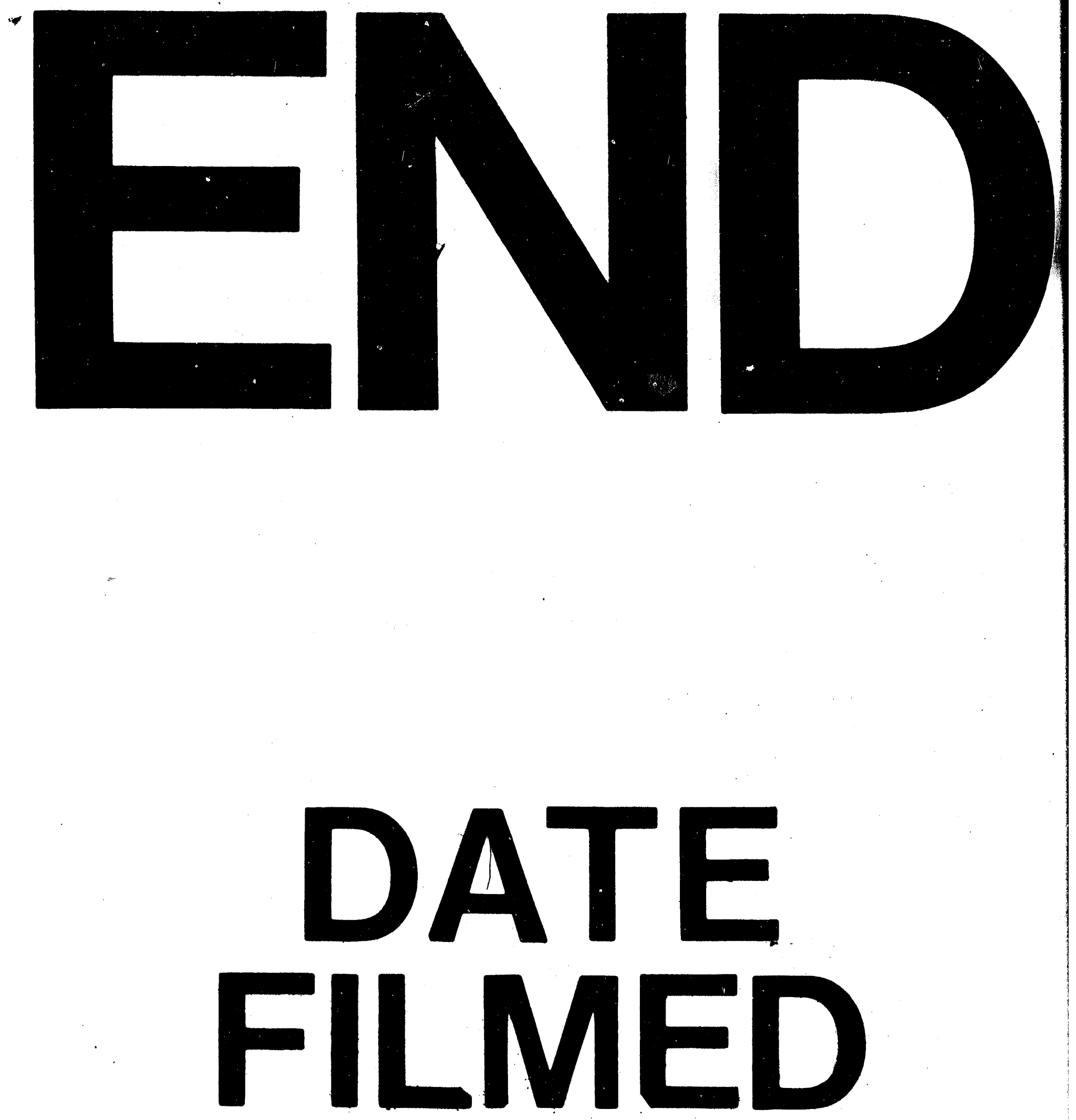

1

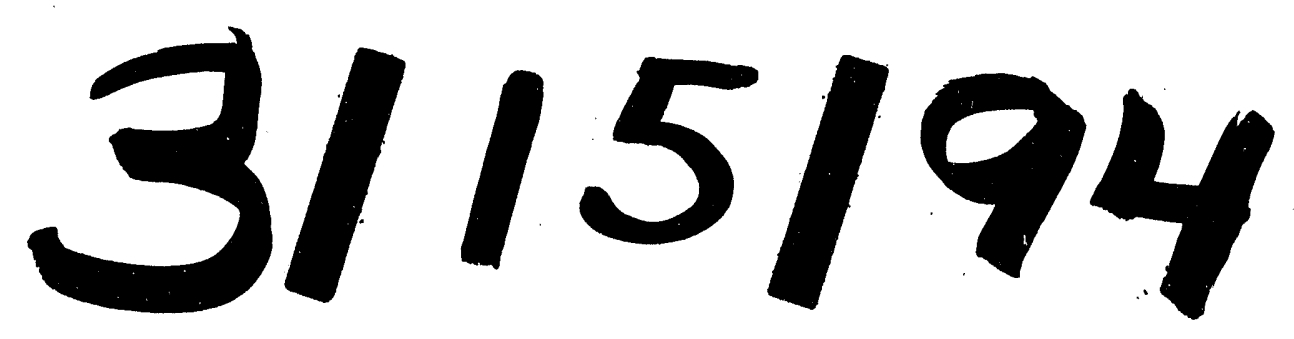


